\title{
Moderate Prenatal Alcohol Exposure Reduces Plasticity and Alters NMDA Receptor Subunit Composition in the Dentate Gyrus
}

\author{
Megan L. Brady, Marvin R. Diaz, Anthony Iuso, Julie C. Everett, C. Fernando Valenzuela, and Kevin K. Caldwell \\ Department of Neurosciences, School of Medicine, University of New Mexico Health Sciences Center, Albuquerque, New Mexico 87131
}

\begin{abstract}
Although it is well documented that heavy consumption of alcohol during pregnancy impairs brain development, it remains controversial whether moderate consumption causes significant damage. Using a limited access, voluntary consumption paradigm, we recently demonstrated that moderate prenatal alcohol exposure (MPAE) is associated with dentate gyrus-dependent learning and memory deficits that are manifested in adulthood. Here, we identified a novel mechanism that may underlie this effect of MPAE. We found that MPAE mice exhibit deficits in NMDA receptor (NMDAR)-dependent long-term potentiation (LTP) in the dentate gyrus. Further, using semiquantitative immunoblotting techniques, we found that the levels of GluN2B subunits were decreased in the synaptic membrane, while levels of C2'-containing GluN1 and GluN3A subunits were increased, in the dentate gyrus of MPAE mice. These data suggest that MPAE alters the subunit composition of synaptic NMDARs, leading to impaired NMDAR-dependent LTP in the dentate gyrus.
\end{abstract}

\section{Introduction}

The range of dysfunctions associated with prenatal alcohol exposure (PAE) is collectively termed fetal alcohol spectrum disorders, which have an estimated prevalence of $1-5 \%$ (Streissguth and O’Malley, 2000; May et al., 2009). Contributing to this high prevalence is the perception that it is safe to drink in moderation during pregnancy, even though a large body of experimental evidence suggests that the developing brain can be significantly altered by moderate PAE (MPAE) (Valenzuela et al., 2012). Notably, studies suggest that MPAE significantly impairs hippocampal-dependent learning and memory (Brady et al., 2012). Because our understanding of the mechanisms underlying these effects of MPAE is limited, there are no effective treatments for MPAE-induced learning and memory deficits.

The dentate gyrus (DG) has been shown to be an important target of MPAE (for review, see Valenzuela et al., 2012). MPAE produces deficits in adult offspring in a delayed non-match to place task and a trace conditioning task (Brady et al., 2012), both of which depend on DG functioning (Shors et al., 2001; Clelland et al., 2009). We hypothesized that these deficits could be a consequence of alterations in synaptic plasticity in the DG secondary to impairments in the function of NMDA receptors (NMDARs),

\footnotetext{
Received March 12, 2012; revised Oct. 31, 2012; accepted Nov. 15, 2012.

Author contributions: M.L.B., C.F.V., and K.K.C. designed research; M.L.B., M.R.D., A.I., J.C.E., and K.K.C. performed research; M.L.B., M.R.D., A.I., J.C.E., and K.K.C. analyzed data; M.L.B., C.F.V., and K.K.C. wrote the paper.

This work was funded by National Institutes of Health Grants T32AA014127 (M.L.B.), F31AA020434 (M.L.B.), R03AA020101 (K.K.C.), P20AA017068 (K.K.C.), R01-AA014973 (C.F.V.), and R01-AA015614 (C.F.V.). We thank Buz Tyler for computer and equipment support, and Andrea Allan and Betty Skipper for assistance with statistical analyses.

The authors declare no competing financial interests.

Correspondence should be addressed to Kevin K. Caldwell, Department of Neurosciences, MSC 08 4740, 1 University of New Mexico, Albuquerque, NM 87131. E-mail: KCaldwell@salud.unm.edu.

DOI:10.1523/JNEUROSCI.1217-12.2013

Copyright $\odot 2013$ the authors $\quad 0270-6474 / 13 / 331062-06 \$ 15.00 / 0$
}

which play a central role in DG synaptic plasticity and have been shown to be affected by MPAE (Costa et al., 2000; Malenka and Bear, 2004).

\section{Materials and Methods}

Animals. All procedures were approved by the University of New Mexico Health Sciences Center Institutional Animal Care and Use Committee. In all studies, mice were anesthetized with ketamine $(250 \mathrm{mg} / \mathrm{kg}$ body weight). For electrophysiological recordings, male offspring were used, with only one animal used from each litter to eliminate litter effects. For subcellular fractionation and subsequent immunoblotting experiments, tissue from two males and two females from each litter were pooled, with the reported number of determination $(n)$ designating one litter; no significant gender differences were noted. For cross-linking studies, one animal per litter with approximately equal numbers of females and males were used.

Prenatal alcohol exposure paradigm. C57BL/6J mice (Jackson Laboratory) were maintained on a reverse $12 \mathrm{~h}$ dark/light schedule (lights on at 8:00 P.M.) in either singly housed (dams) or group-housed (offspring used in all studies) cages. The MPAE paradigm has been previously described (Brady et al., 2012). All measurements were conducted on adult (2- to 5-month-old) offspring.

Electrophysiological recordings. Coronal brain slices $(400 \mu \mathrm{m})$ were prepared as previously described (Samudio-Ruiz et al., 2009). Except where indicated, slices were allowed to recover in artificial CSF as previously described (Malleret et al., 2010). Extracellular recordings were made from the middle third of the molecular layer after medial perforant path (MPP) stimulation in slices maintained at $28-30^{\circ} \mathrm{C}$ and perfused at $3.6 \mathrm{ml} / \mathrm{min}$ using an Axopatch 200B amplifier (Molecular Devices). MPP recordings were confirmed by the observation of paired-pulse depression in ionotropic receptor-dependent field EPSP (fEPSP) recordings. For the high-frequency stimulation (HFS) long-term potentiation (LTP) recordings and whole-cell patch-clamp recordings, slices were prepared as previously described (Everett et al., 2012). Stimulation intensity was set to elicit $40-60 \%$ of the maximal response based on input/output (I/O) 

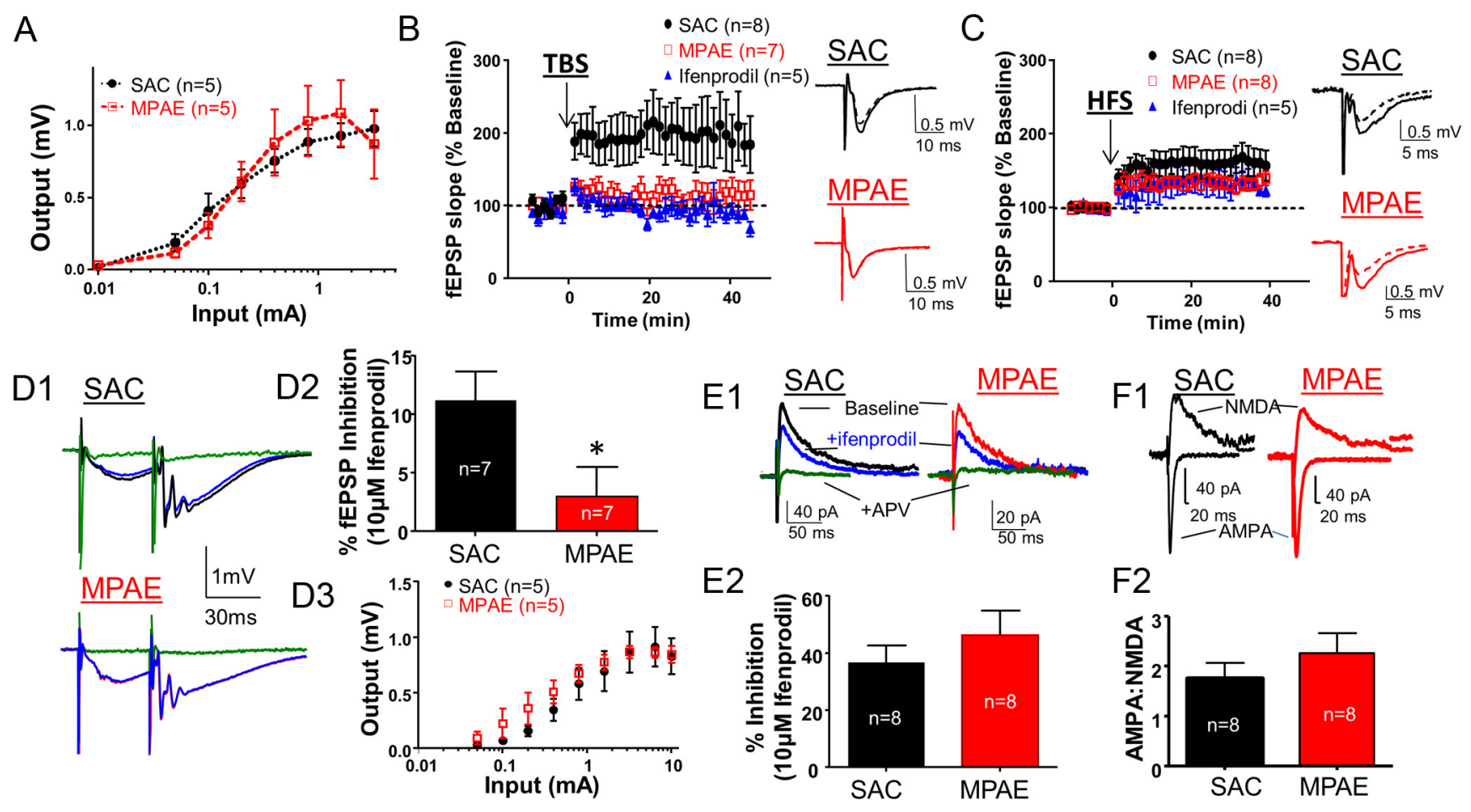

F2

Figure 1. MPAE impaired NMDAR-dependent LTP and reduced GluN2B-containing NMDAR contribution to fEPSPs in the dentate gyrus. $A$, lonotropic glutamate receptor-mediated I/O curves from SAC and MPAE slices. B, TBS-induced LTP in DG was blocked by ifenprodil (10 $\mu \mathrm{M})$ and by MPAE. C, HFS-induced LTP was not significantly affected by MPAE or by ifenprodil. D1, D2, Ifenprodil-induced inhibition of NMDAR-dependent fEPSP area was significantly decreased in MPAE mice compared with SAC. D3, NMDAR-mediated I/0 curves from SAC and MPAE slices. E1, E2, Ifenprodil-induced inhibition of NMDAR-EPSCs did not differ between the SAC and MPAE groups. $\boldsymbol{F 1}, \boldsymbol{F 2}$, AMPA/NMDA was not different between the SAC and MPAE groups.

curves. Stimulation duration was $75 \mu$ s and test stimuli were delivered at $0.033 \mathrm{~Hz}$ in the presence of $50 \mu \mathrm{M}$ picrotoxin (Tocris Bioscience).

NMDAR-mediated fEPSPs were recorded in the presence of low $\mathrm{Mg}^{2+}$ $(0.1 \mu \mathrm{M}), 10 \mu \mathrm{M}$ 2,3-dioxo-6-nitro-1,2,3,4-tetrahydrobenzo[f] quinoxaline7-sulfonamide (NBQX) (Tocris Bioscience), and $10 \mu \mathrm{M}$ glycine (Bio-Rad). To determine GluN2B contribution to NMDAR-mediated fEPSPs, we used ifenprodil (10 $\mu \mathrm{m}$; Tocris Bioscience). Theta burst stimulation (TBS; nine bursts of four pulses at $100 \mathrm{~Hz}, 200 \mathrm{~ms}$ interburst interval, 5 min intertrain interval) LTP was induced as described previously (Malleret et al., 2010). HFS consisted of 3 trains ( $1 \mathrm{~s}$ at $100 \mathrm{~Hz}$ each) with an intertrain interval of $15 \mathrm{~s}$.

For whole-cell patch-clamp recordings, we used the $\mathrm{Cs}_{2} \mathrm{SO}_{4}$-based internal solution that was previously described (D'Angelo et al., 1999). A concentric bipolar stimulating electrode was placed in the molecular layer, 200-300 $\mu \mathrm{m}$ from the patched cell. Stable EPSCs were evoked with an average stimulation intensity of $0.09 \mathrm{~mA}(75 \mu$ s pulse duration every $20 \mathrm{~s}$ ) in the presence of $50 \mu \mathrm{M}$ picrotoxin. After recording composite EPSCs at $-70 \mathrm{mV}$, the membrane potential was slowly changed to +40 $\mathrm{mV}$. NBQX $(10 \mu \mathrm{M})$ was applied for $5 \mathrm{~min}$ and NMDAR-mediated EPSCs were recorded. Ifenprodil $(10 \mu \mathrm{M})$ was applied for $10 \mathrm{~min}$, followed by NMDAR blockade with APV $(20 \mu \mathrm{M})$.

Synaptic and nonsynaptic fraction preparation and immunoblotting of NMDAR subunits. The DG was microdissected and sonicated in homogenization buffer (Samudio-Ruiz et al., 2010) before storage at $-80^{\circ} \mathrm{C}$. Subcellular fractionation was performed as described by Samudio-Ruiz et al. (2010) with the subsequent isolation of synaptic (Triton-insoluble particulate, $\mathrm{TxP}$ ) and nonsynaptic (Triton-soluble, TxS) fractions, as described by Goebel-Goody et al. (2009). Protein concentrations of the fractions were determined using the Bio-Rad DC Protein Assay Kit. Approximately $80 \%$ of the homogenate protein was accounted for in the various subcellular fractions (data not shown).

Immunoblotting was performed as described by Samudio-Ruiz et al. (2010) using the following antibodies: anti-NR2A rabbit polyclonal antibody (1:1000 synaptic, 1:500 nonsynaptic, PhosphoSolutions); antiNR2B rabbit polyclonal antibody (1:1000 synaptic, 1:250 nonsynaptic,
PhosphoSolutions); anti-GluN1 C1, C2, or C2' rabbit polyclonal antibodies (1:500, a generous gift from Dr. Michael Browning, University of Colorado, Denver, CO); anti-NR3A rabbit polyclonal antibody (1:500, Santa Cruz Biotechnology Inc.), anti-PSD-95 rabbit polyclonal antibody (1:1000, Cell Signaling Technology), anti- $\beta$-actin rabbit polyclonal antibody (1:2000, Cell Signaling Technology) or anti-GABA ${ }_{\mathrm{A}} \mathrm{R} \alpha 4$ rabbit polyclonal antibody (1:500, Santa Cruz Biotechnology). For each sample, the anti-NMDAR subunit immunoreactivity was normalized to either anti-PSD-95 (TxP fractions) or anti- $\beta$-actin immunoreactivity (TxS fractions and dentate gyrus slices); levels of these two proteins were not different between saccharin control (SAC) and MPAE animals. Optical density values were obtained using Image $(\mathrm{NIH})$ or LI-COR image software.

Crosslinking of surface receptors. Surface expression of NMDAR subunits present in DG tissue slices microdissected from coronal brain slices (see above) was determined using BS $^{3}$ (bis[sulfosuccinimidyl] suberate) crosslinking, as described by Grosshans et al. (2002). DG microslices from an animal were pooled, and then one-half of the slices was treated with $\mathrm{BS}^{3}$, while the other half was not. Sonicated tissue lysates were analyzed by immunoblotting, as described above, with the exception that detection was performed with fluorescent dye-labeled secondary antibodies using an Odyssey imaging system (LI-COR).

\section{Results}

We used a limited access paradigm that we have shown to yield relatively moderate alcohol levels in dams (Brady et al., 2012). In the present study, offspring were derived from litters born to dams having an average consumption of $5.99 \pm 0.23 \mathrm{~g}$ of $\mathrm{EtOH} / \mathrm{kg}$ of body weight/d $(n=28)$; blood ethanol concentrations measured at the end of the $4 \mathrm{hr}$ drinking period from dams whose litters were not used for experiments were $90.5 \pm 11.61$ $\mathrm{mg} / \mathrm{dl}(n=11)$.

We found no effect of MPAE on I/O curves for ionotropic glutamatergic receptor-mediated fEPSPs (Fig. 1A; two-way 
A1
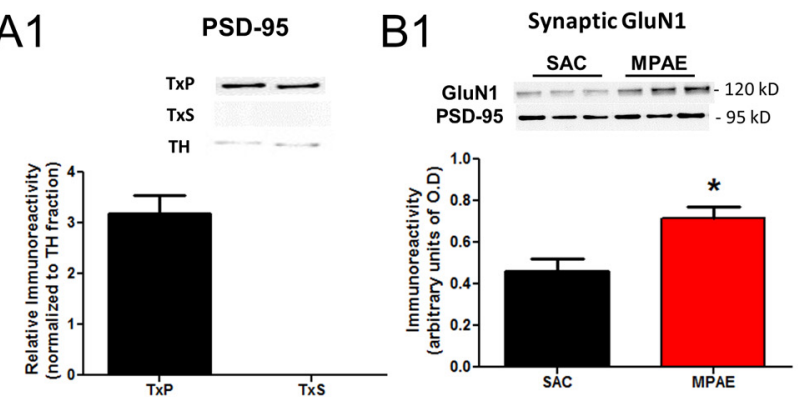

A2

$\mathrm{GABA}_{\mathrm{A}} \mathrm{R} \alpha \mathbf{4}$

B3

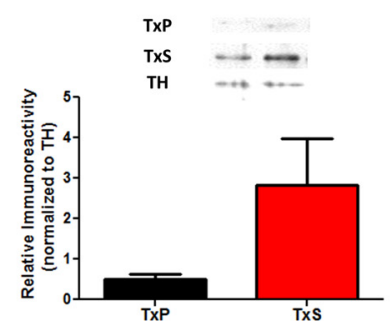

E

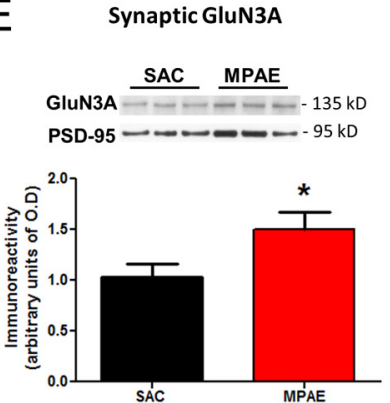

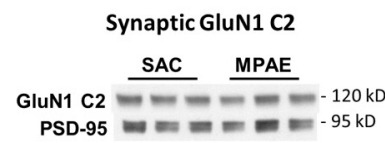

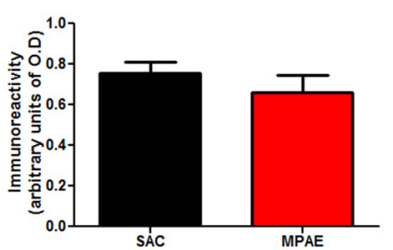

F1
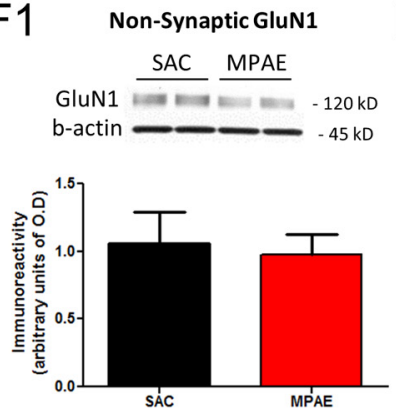
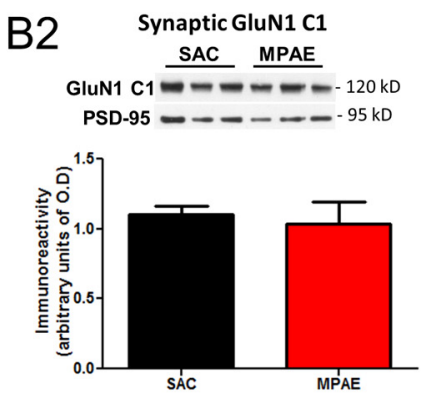

B4
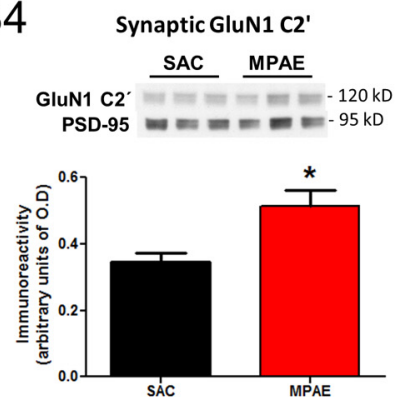

F2
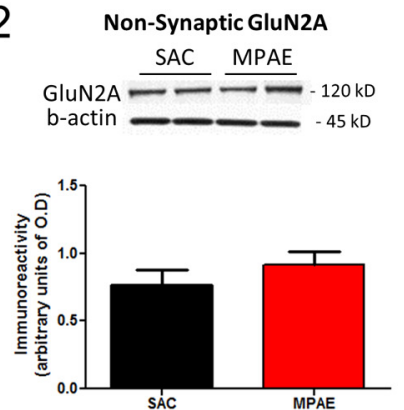

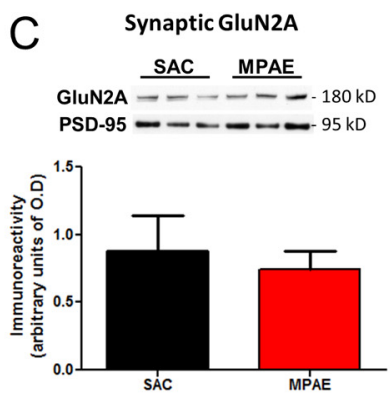

D Synaptic GluN2B
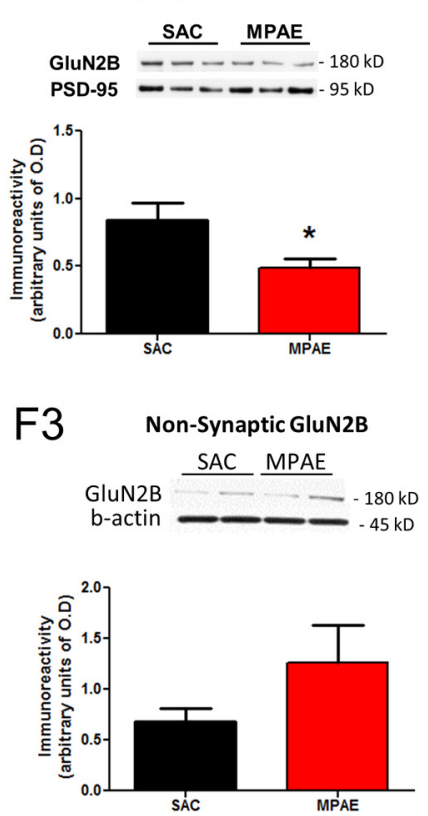

Figure 2. MPAE altered NMDAR subunit levels in the synaptic fraction of the dentate gyrus. $A$, Characterization of synaptic and nonsynaptic fractions. Data were normalized to the amount present in total homogenate (TH). In control tissue, PSD-95 was enriched approximately threefold in the synaptic (TxP) fraction compared with the nonsynaptic (TxS) fraction ( $\left.n=4 ; A_{1}\right)$ and GABA $A_{A} \alpha 4$ subunit was enriched approximately twofold in the TxS fraction compared with the TxP fraction $(n=4 ; \boldsymbol{A 2})$. $\boldsymbol{B}$, GluN1 (B1) subunit levels, specifically $C 2^{\prime}$-containing GluN1 subunit levels ( $\left.\boldsymbol{B} 4\right)$, were significantly increased in MPAE mice compared with SAC (GluN1: $n=7,{ }^{*} p<0.05 ;\left(2^{\prime}: n=9,{ }^{* *} p<0.01\right)$, with no changes in C1-containing (B2) or C2-containing (B3) GluN1 subunits. C, GluN2A subunit levels were unchanged by MPAE. $\boldsymbol{D}$, GluN2B subunit levels were significantly decreased by MPAE mice $\left(n=7,{ }^{*} p<0.05\right)$. $\boldsymbol{E}$, GluN3A subunit levels were significantly increased in MPAE mice compared with SAC $\left(n=8,{ }^{*} p<0.05\right)$. $\boldsymbol{F}$, Levels of GluN1 $(\boldsymbol{F} 1)$, GluN2A $(\boldsymbol{F 2})$, and GluN2B $(\boldsymbol{F} 3)$ did not differ in the nonsynaptic fraction of SAC and MPAE mice.

ANOVA, effect of treatment $F_{(1,60)}=0.10$, n.s., effect of input $F_{(7,60)}=16.53, p<0.0001$, interaction $F_{(7,60)}=0.32$, n.s.) or the paired-pulse ratio of these fEPSPs (SAC $0.95 \pm 0.03$, MPAE $0.90 \pm 0.05$, n.s., $n=6$ ).

We examined whether MPAE altered NMDAR-dependent LTP in the DG. TBS elicited LTP in slices from the SAC group (Fig. $1 B$ ). We confirmed that this LTP was NMDAR-dependent by blocking it with $10 \mu \mathrm{M} \mathrm{MK}-801$ and $25 \mu \mathrm{M}$ AP-5 $(n=5$, data not shown). Ifenprodil $(10 \mu \mathrm{M})$ impaired LTP induction (repeated-measures two-way ANOVA, effect of time $F_{(36,360)}=$ 2.88, $p=0.001$, effect of treatment $F_{(1,10)}=5.78, p<0.05$, interaction $F_{(36,360)}=2.99, p=0.0001$ ), indicating that the TBSelicited LTP was GluN2B subunit-dependent (Fig. 1B). We compared the effects of TBS in SAC and MPAE animals; repeated measures two-way ANOVA found a significant effect of time $\left(F_{(36,432)}=4.66, p=0.0001\right)$, treatment $\left(F_{(1,12)}=5.37, p<0.05\right)$, and an interaction $\left(F_{(36,432)}=2.75, p=0.0001\right.$; Fig. $\left.1 B\right)$, suggesting that MPAE animals have GluN2B NMDAR-dependent LTP deficits. As a control, we examined the effect of MPAE on LTP induced by a HFS paradigm. In slices from SAC mice, HFS LTP was not significantly different from TBS LTP (Fig. $1 C$ vs $B$; n.s. by two-way ANOVA). However, neither MPAE nor ifenprodil significantly inhibited HFS LTP (Fig. 1C).

Having observed a deficit in GluN2B-dependent LTP, we assessed the contribution of GluN2B-containing NMDARs to basal synaptic transmission in SAC and MPAE mice by measuring NMDAR-mediated fEPSPs in the absence and presence of ifenprodil. fEPSPs were blocked by $10 \mu \mathrm{MAP}-5$, confirming that they were NMDAR-dependent (Fig. 1D1). The ifenprodil-induced suppression of the first fEPSP (determined by measuring area under the curve) was significantly decreased by $\operatorname{MPAE}\left(t_{(12)}=\right.$ 2.33, $p<0.05$; Fig. 1D1,D2). No change in paired-pulse ratio, either between SAC and MPAE or before and after ifenprodil, was observed (SAC without ifenprodil $2.54 \pm 0.36$, SAC with ifenprodil 2.62 \pm 0.28 , MPAE without ifenprodil $2.34 \pm 0.21$, MPAE with ifenprodil $2.53 \pm 0.30)$. I/O curves for NMDAR-dependent fEPSPs were not significantly different (Fig. 1D3). Figure 1, E and $F$, shows that there were no differences either in the ifenprodilinduced suppression of NMDAR-mediated EPSCs or the AMPA/ NMDA ratios between SAC and MPAE mice (n.s. by unpaired $t$ test) using whole-cell recordings. 

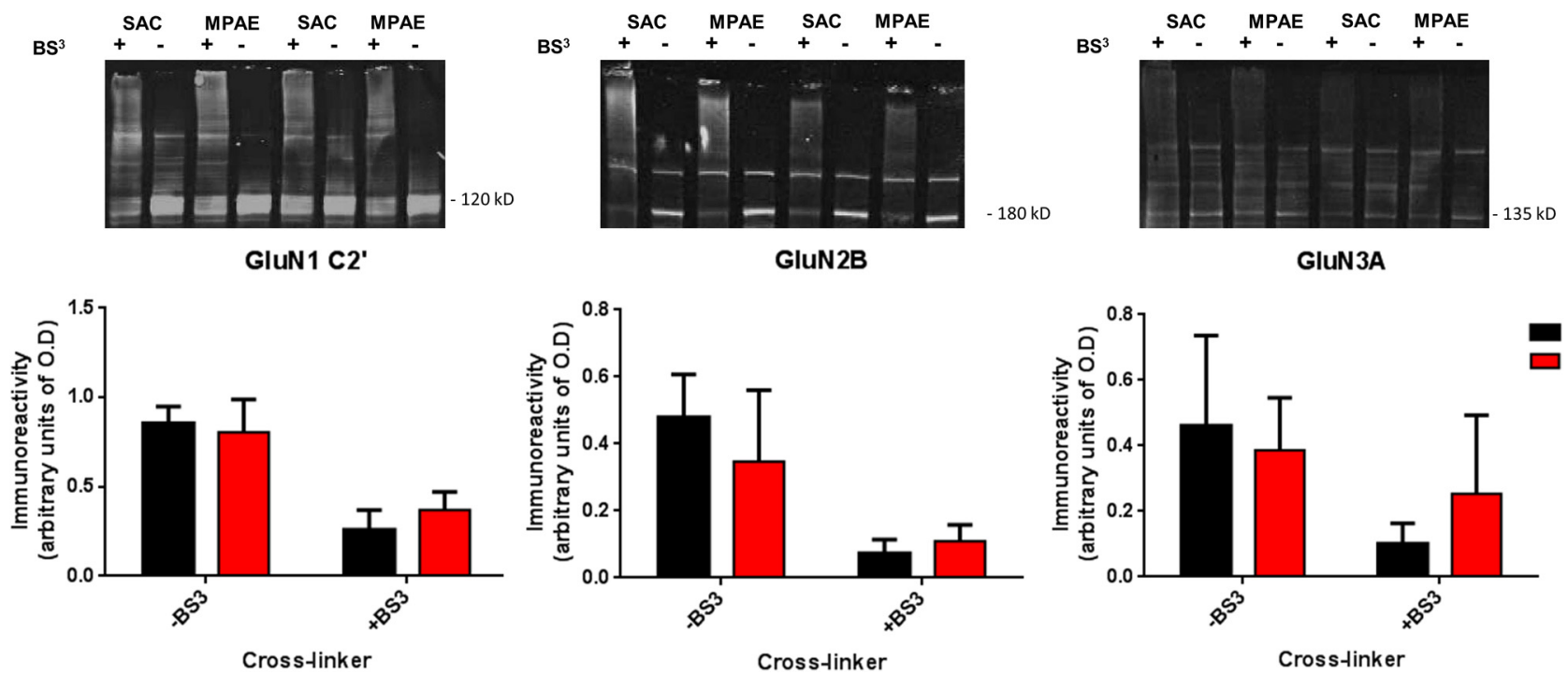

Figure 3. Surface expression of GluN1 $\mathrm{C}^{\prime}$-containing, GluN2B and GluN3A subunits, measured indirectly using the membrane-impermeable cross-linker BS ${ }^{3}$, did not differ in SAC and MPAE dentate gyrus tissue slices. Tissue slices were treated with $(+)$ or without $(-) B S^{3}$ membrane impermeable cross-linker and then analyzed for NMDAR subunit levels, as described in Materials and Methods.

We next determined whether the observed deficit in NMDAR-dependent synaptic plasticity was associated with alterations in NMDAR levels and/or synaptic localization in the DG. Subcellular fractions enriched in synaptic (TxP) and nonsynaptic (TxS) protein markers, postsynaptic density-protein 95 (PSD95) and $\mathrm{GABA}_{\mathrm{A}} \mathrm{R} \alpha 4$ subunit (Chandra et al., 2006), respectively, were prepared from control DG tissue. PSD-95 was detected only in the synaptic fraction (Fig. 2A1) and $\mathrm{GABA}_{\mathrm{A}} \mathrm{R} \alpha 4$ (Fig. 2A2) was enriched in the nonsynaptic fraction, indicating appropriate subcellular fractionation. Importantly, PSD-95 and $\mathrm{GABA}_{\mathrm{A}} \mathrm{R} \alpha 4$ were distributed similarly in SAC and MPAE tissue (data not shown), demonstrating that MPAE does not alter the subcellular fractionation of the tissue.

We assessed NMDAR GluN1, GluN2A, GluN2B, and GluN3A subunit protein levels in synaptic and nonsynaptic fractions isolated from DG tissue using semiquantitative immunoblotting. We found a significant increase in synaptic GluN1 subunit levels in MPAE DG $\left(t_{(11)}=3.057, n=7 ; p<0.05\right.$, Fig. $\left.2 B 1\right)$, leading us to examine the expression of GluN1 C-terminal splice variants. Eight splice variants of the GluN1 subunit exist, four of which arise from alternate splice sites in the $\mathrm{C}$ terminus (GluN1-1: C1 and C2 cassettes, GluN1-2: C2 cassette, GluN1-3: C1 and C2' cassettes, GluN1-4: C2' cassette); these C-terminal variants influence NMDAR trafficking (Horak and Wenthold, 2009). We found an increase in $\mathrm{C}^{\prime}$ - -containing GluN1 subunits $\left(t_{(16)}=\right.$ 3.102, $n=7, p<0.01$, Fig. 2B4), with no change in $\mathrm{C} 1-$ or C2-containing GluN1 subunits $(n=9$, n.s., Fig. $2 B 2, B 3)$.

GluN2 subunits consist of four subtypes (A-D), which determine receptor kinetics and coupling to downstream signaling systems, while GluN3 subunits consist of two subtypes (A and B), which can convert the NMDAR into an excitatory glycine receptor (Smothers and Woodward, 2009). We found that DG GluN2B subunit levels were decreased by $\operatorname{MPAE}\left(t_{(11)}=2.317\right.$, $n=7, p<0.05$; Fig. $2 D)$ and GluN2A subunit levels were unchanged (Fig. $2 C$ ) in MPAE relative to SAC DG.

Given that there was an increase in $\mathrm{C}_{2}$ '-containing GluN1 subunit expression without a matching increase in one of the GluN2 subunits, we investigated whether there was a corresponding increase in the level of one of the GluN3 subunits, specifically GluN3A. In MPAE animals, GluN3A levels were found to be increased compared with SAC $\left(t_{(14)}=2.162, n=8\right.$; $p<0.05$; Fig. $2 E$ ).

We also examined NMDAR subunit levels in the nonsynaptic fraction, since studies have determined that extrasynaptic NMDAR subunit activation is associated with ERK 1/2 and CREB deactivation (Ivanov et al., 2006), which may affect LTP expression. We found no significant differences in the levels of GluN1, GluN2A, or GluN2B in the nonsynaptic fraction in MPAE animals compared with SAC (Fig. 2F1-F3). Attempts to measure the expression of GluN3A expression in the nonsynaptic fraction were unsuccessful, presumably due to the very low expression or absence of expression of the subunit in this compartment.

Finally, we assessed surface expression of GluN1 C2'containing, GluN2B and GluN3A subunits in DG microdissected slices using the membrane-impermeable cross-linker BS ${ }^{3}$ (Fig. 3). Cross-linking of cell surface receptors results in their migrating as high molecular weight bands on the gel/immunoblot, while intracellular receptors migrate at the expected apparent molecular weight. By measuring the level of this latter pool of receptors, an indirect measure of surface expression is obtained. Two-way ANOVA revealed that, for each subunit, while there was a significant effect of the cross-linker, there was not a significant effect of prenatal exposure, indicating that total surface expression of these subunits was not affected by MPAE.

\section{Discussion}

We have shown that MPAE produces neurophysiological and neurochemical alterations in the adult mouse DG. While MPAE did not affect basal transmission mediated by either NMDARs or AMPARs, it was associated with impaired NMDAR-dependent LTP evoked by TBS and decreased contribution of GluN2Bcontaining NMDARs to fEPSPs recorded in the molecular layer where granule cell dendrites are located. To our knowledge, although other studies have examined the effect of MPAE on LTP in the DG (Sutherland et al., 1997; Varaschin et al., 2010), none determined whether observed deficits were NMDAR-dependent. Using immunoblotting techniques, we found that GluN2B levels 
were decreased, while $\mathrm{C} 2$ '-containing GluN1 and GluN3A levels were increased, in an enriched synaptic fraction.

The decrease in synaptic GluN2B levels and function recorded in the immunoblotting and electrophysiological studies, respectively, may be a significant contributing factor to the LTP deficit seen in MPAE mice, as previous research has implicated GluN2B in LTP expression in the DG (Ge et al., 2007; Vasuta et al., 2007). GluN2B-specific antagonist application during acquisition of a trace conditioning paradigm blocks both potentiation of evoked fEPSPs in the dentate gyrus in vivo and learning in the task (Valenzuela-Harrington et al., 2007). A recent study found that, early in development, switching the GluN2B subunit with the GluN2A subunit to restore NMDAR-mediated currents did not rescue GluN2B loss of function, primarily due to loss of signaling downstream of GluN2B (Wang et al., 2011). Thus, a decrease in GluN2B receptor levels in MPAE animals may alter downstream signaling, leading to the observed LTP deficits. In support of this, we previously demonstrated reduced NMDAR-dependent activation of extracellular signal-regulated kinase $1 / 2$ in the DG of MPAE mice (Samudio-Ruiz et al., 2009).

An interesting finding of our study is that MPAE affected ifenprodil sensitivity of extracellularly recorded fEPSPs but not EPSCs recorded in the whole-cell patch-clamp configuration. A possible explanation is that the signals obtained in fEPSP recording are generated by NMDARs expressed in proximal and distal segments of the dendrites located in the molecular layer, whereas signals recorded in the patch-clamp configuration are generated by more proximally expressed NMDARs. Intriguingly, LTP extracellularly recorded in the DG of mice was shown to be blocked by ifenprodil (Vasuta et al., 2007) but not LTP recorded in the whole-cell configuration from mature DG neurons (Ge et al., 2007). Moreover, the small effect of ifenprodil on NMDAR fEPSPs may not explain the complete blockade of LTP that we observed; Ge et al. (2007) reported that 75\% blockade of NMDAR EPSCs is required to observe LTP inhibition in adult-born DG cells. Therefore, an alternative explanation is that additional actions may contribute to the effects of ifenprodil, as Delaney et al. (2012) recently reported that $10 \mu \mathrm{M}$ ifenprodil can partially block P/Q-type calcium channels.

Increases in synaptic GluN1 and GluN3A subunits may also affect LTP expression in MPAE animals. The increase in synaptic $\mathrm{C} 2$ '-containing GluN1 subunit levels, with no associated change in C1-containing subunits, suggests that the GluN1-4 splice variant, predominant variant in the hippocampus (Laurie and Seeburg, 1994), is elevated in MPAE mouse DG. The GluN1-4 splice variant lacks the $\mathrm{C} 1$ cassette, which contains two endoplasmic reticulum retention signals that impede forward trafficking, and contains the $\mathrm{C} 2$ ' cassette, which has an enhancing effect on forward trafficking (Horak and Wenthold, 2009). Thus, an increase in C2' -containing GluN1 subunits may account for the observed increase in synaptic, total GluN1subunit levels. GluN3A subunits have been shown to preferentially traffic to the surface with GluN1-4 (Smothers and Woodward, 2009), potentially leading to the increase in synaptic GluN3A levels in the MPAE mice.

Diheterotetrameric GluN1/GluN3A NMDARs are excitatory glycine receptors, generally considered to be impermeable to $\mathrm{Ca}^{2+}$. Thus, an increase in the levels of GluN1/GluN3Acontaining NMDARs may modify $\mathrm{Ca}^{2+}$ influx after glutamatergic stimulation, having effects on signaling downstream of NMDARs. However, although GluN1/GluN3A receptors have been found to traffic to the surface in transfected Xenopus oocytes, GluN3A requires the presence of either GluN3B or GluN2 to traffic to the surface in HEK293 cells (Low and Wee,
2010), indicating that GluN1/GluN3A diheterotetrameric receptors may not be present at the surface in mammalian cells. Unfortunately, we were unable to immunoblot for GluN3B using commercially available antibodies in our system, and could not determine whether GluN3B levels were increased. GluN3A incorporation into GluN1/GluN2-containing receptors would alter the function of the receptor by decreasing $\mathrm{Ca}^{2+}$ permeability and $\mathrm{Mg}^{2+}$ blockade (Perez-Otano et al., 2001). GluN3A levels are high soon after birth, and quickly decrease during the first $21 \mathrm{~d}$, corresponding to the time of synaptic maturation (Perez-Otano et al., 2001). Although the role of GluN3A in synaptic maturation and plasticity has not been fully examined, overexpression of GluN3A in the CA1 of the hippocampus during adulthood has been reported to limit synapse potentiation (Roberts et al., 2009), which may explain MPAE-induced LTP impairment.

Although other factors may be involved in the LTP deficits seen in adult MPAE animals, our study implicates alterations in NMDAR subunit composition, presumably at dendritic synaptic membranes, as significant contributors. Given the critical role that NMDARs play in LTP, it is likely that the GluN2B deficit and/or the $\mathrm{C}^{\prime}$-containing GluN1 and GluN3A increases contribute to the LTP deficits seen in MPAE animals, and may be targets for therapeutic intervention.

\section{References}

Brady ML, Allan AM, Caldwell KK (2012) A limited access mouse model of prenatal alcohol exposure that produces long-lasting deficits in hippocampal-dependent learning and memory. Alcohol Clin Exp Res 36:457-466. Medline

Chandra D, Jia F, Liang J, Peng Z, Suryanarayanan A, Werner DF, Spigelman I, Houser CR, Olsen RW, Harrison NL, Homanics GE (2006) GABAA receptor alpha 4 subunits mediate extrasynaptic inhibition in thalamus and dentate gyrus and the action of gaboxadol. Proc Natl Acad Sci U S A 103:15230-15235. CrossRef Medline

Clelland CD, Choi M, Romberg C, Clemenson GD Jr, Fragniere A, Tyers P, Jessberger S, Saksida LM, Barker RA, Gage FH, Bussey TJ (2009) A functional role for adult hippocampal neurogenesis in spatial pattern separation. Science 325:210-213. CrossRef Medline

Costa ET, Savage DD, Valenzuela CF (2000) A review of the effects of prenatal or early postnatal ethanol exposure on brain ligand-gated ion channels. Alcohol Clin Exp Res 24:706-715. CrossRef Medline

D’Angelo E, Rossi P, Armano S, Taglietti V (1999) Evidence for NMDA and mGlu receptor-dependent long-term potentiation of mossy fiber-granule cell transmission in rat cerebellum. J Neurophysiol 81:277-287. Medline

Delaney AJ, Power JM, Sah P (2012) Ifenprodil reduces excitatory synaptic transmission by blocking presynaptic $\mathrm{P} / \mathrm{Q}$ type calcium channels. J Neurophysiol 107:1571-1575. CrossRef Medline

Everett JC, Licón-Muñoz Y, Valenzuela CF (2012) Effects of third trimesterequivalent ethanol exposure on $\mathrm{Cl}^{-}$co-transporter expression, network activity, and GABAergic transmission in the CA3 hippocampal region of neonatal rats. Alcohol 46:595-601. CrossRef Medline

Ge S, Yang CH, Hsu KS, Ming GL, Song H (2007) A critical period for enhanced synaptic plasticity in newly generated neurons of the adult brain. Neuron 54:559-566. CrossRef Medline

Goebel-Goody SM, Davies KD, Alvestad Linger RM, Freund RK, Browning MD (2009) Phospho-regulation of synaptic and extrasynaptic $\mathrm{N}$-methyl-D-aspartate receptors in adult hippocampal slices. Neuroscience 158:1446-1459. CrossRef Medline

Grosshans DR, Clayton DA, Coultrap SJ, Browning MD (2002) LTP leads to rapid surface expression of NMDA but not AMPA receptors in adult rat CA1. Nat Neurosci 5:27-33. CrossRef Medline

Horak M, Wenthold RJ (2009) Different roles of C-terminal cassettes in the trafficking of full-length NR1 subunits to the cell surface. J Biol Chem 284:9683-9691. CrossRef Medline

Ivanov A, Pellegrino C, Rama S, Dumalska I, Salyha Y, Ben-Ari Y, Medina I (2006) Opposing role of synaptic and extrasynaptic NMDA receptors in regulation of the extracellular signal-regulated kinases (ERK) activity in cultured rat hippocampal neurons. J Physiol 572:789-798. Medline

Laurie DJ, Seeburg PH (1994) Regional and developmental heterogeneity in 
splicing of the rat brain NMDAR1 mRNA. J Neurosci 14:3180-3194. Medline

Low CM, Wee KS (2010) New insights into the not-so-new NR3 subunits of $\mathrm{N}$-methyl-D-aspartate receptor: localization, structure, and function. Mol Pharmacol 78:1-11. CrossRef Medline

Malenka RC, Bear MF (2004) LTP and LTD: an embarrassment of riches. Neuron 44:5-21. CrossRef Medline

Malleret G, Alarcon JM, Martel G, Takizawa S, Vronskaya S, Yin D, Chen IZ, Kandel ER, Shumyatsky GP (2010) Bidirectional regulation of hippocampal long-term synaptic plasticity and its influence on opposing forms of memory. J Neurosci 30:3813-3825. CrossRef Medline

May PA, Gossage JP, Kalberg WO, Robinson LK, Buckley D, Manning M, Hoyme HE (2009) Prevalence and epidemiologic characteristics of FASD from various research methods with an emphasis on recent inschool studies. Dev Disabil Res Rev 15:176-192. CrossRef Medline

Perez-Otano I, Schulteis CT, Contractor A, Lipton SA, Trimmer JS, Sucher NJ, Heinemann SF (2001) Assembly with the NR1 subunit is required for surface expression of NR3A-containing NMDA receptors. J Neurosci 21:1228-1237. Medline

Roberts AC, Díez-Garcia J, Rodriguiz RM, López IP, Luján R, MartínezTurrillas R, Picó E, Henson MA, Bernardo DR, Jarrett TM, Clendeninn DJ, López-Mascaraque L, Feng G, Lo DC, Wesseling JF, Wetsel WC, Philpot BD, Pérez-Otaño I (2009) Downregulation of NR3A-containing NMDARs is required for synapse maturation and memory consolidation. Neuron 63:342-356. CrossRef Medline

Samudio-Ruiz SL, Allan AM, Valenzuela CF, Perrone-Bizzozero NI, Caldwell KK (2009) Prenatal ethanol exposure persistently impairs NMDA receptor-dependent activation of extracellular signal-regulated kinase in the mouse dentate gyrus. J Neurochem 109:1311-1323. CrossRef Medline

Samudio-Ruiz SL, Allan AM, Sheema S, Caldwell KK (2010) Hippocampal $\mathrm{N}$-methyl-D-aspartate receptor subunit expression profiles in a mouse model of prenatal alcohol exposure. Alcohol Clin Exp Res 34:342-353. CrossRef Medline
Shors TJ, Miesegaes G, Beylin A, Zhao M, Rydel T, Gould E (2001) Neurogenesis in the adult is involved in the formation of trace memories. Nature 410:372-376. CrossRef Medline

Smothers CT, Woodward JJ (2009) Expression of glycine-activated diheteromeric NR1/NR3 receptors in human embryonic kidney 293 cells Is NR1 splice variant-dependent. J Pharmacol Exp Ther 331:975-984. CrossRef Medline

Streissguth AP, O’Malley K (2000) Neuropsychiatric implications and longterm consequences of fetal alcohol spectrum disorders. Semin Clin Neuropsychiatry 5:177-190. CrossRef Medline

Sutherland RJ, McDonald RJ, Savage DD (1997) Prenatal exposure to moderate levels of ethanol can have long-lasting effects on hippocampal synaptic plasticity in adult offspring. Hippocampus 7:232-238. CrossRef Medline

Valenzuela CF, Morton RA, Diaz MR, Topper L (2012) Does moderate drinking harm the fetal brain? Insights from animal models. Trends Neurosci 35:284-292. CrossRef Medline

Valenzuela-Harrington M, Gruart A, Delgado-García JM (2007) Contribution of NMDA receptor NR2B subunit to synaptic plasticity during associative learning in behaving rats. Eur J Neurosci 25:830-836. CrossRef Medline

Varaschin RK, Akers KG, Rosenberg MJ, Hamilton DA, Savage DD (2010) Effects of the cognition-enhancing agent ABT-239 on fetal ethanolinduced deficits in dentate gyrus synaptic plasticity. J Pharmacol Exp Ther 334:191-198. CrossRef Medline

Vasuta C, Caunt C, James R, Samadi S, Schibuk E, Kannangara T, Titterness AK, Christie BR (2007) Effects of exercise on NMDA receptor subunit contributions to bidirectional synaptic plasticity in the mouse dentate gyrus. Hippocampus 17:1201-1208. CrossRef Medline

Wang CC, Held RG, Chang SC, Yang L, Delpire E, Ghosh A, Hall BJ (2011) A critical role for GluN2B-containing NMDA receptors in cortical development and function. Neuron 72:789-805. CrossRef Medline 